\title{
ROLE OF BHRAMARI PRANAYAM IN MANAGEMENT OF HYPERTENSION
}

\section{Dr. M. K. Taneja*}

\author{
${ }^{*}$ Corresponding Author
}

ABSTRACT Essential hypertension is a rise in blood pressure and in $90 \%$ it is of unknown cause. Secondary hypertension which is the result of a pathology, chronic kidney disease, narrowing of the aorta or endocrine disorder. The predisposing factors may be single or multiple are genetic, environmental, behavioural including work stress and food habits. the first 6 lines of yog sutra control body mind and soul. atha yoga-anusasanam, yogas-chitta-vrattinirodhah, tadadrastuhsvarupe-'vasthanam,

BHRAMARI - HUMMING-SHABAD-is a phonatory respiratory exercise releases nitric oxide. Bhramari increases the production of nitric oxide by 16 times. Nitric oxide is omnipresent a pleiotropic signalling molecule, plays important role in almost every biological system and controls hypertension

Material And Method

We randomly selected 82 patients of essential hypertension from the outdoor of hospital, out of which 40 were of uncontrolled hypertension. Detailed case history, family history, duration of illness, drug type, regularity and diet pattern were questioned and recorded. Blood Pressure (BP), pulse rate (PR), Oxygen saturation (Spo2) were monitored before and after meditation.

Results

The most common aggravating factor was sedentary life style (90\%) followed by work stress (30\%) commonest warning symptom was tiredness. There was reduction of $18 \mathrm{~mm}$ systolic and $12 \mathrm{~mm} \mathrm{Hg}$ in diastolic blood pressure.

Conclusion

Bhramari Pranayama, focused concentration (Shiv Dhyan) and slow deep abdominal breathing with extended exhalation leads to calmness reduces hyperactive sympathetic activity and enhances parasympathetic activity. The average lowering of blood pressure was observed by $18 / 12 \mathrm{~mm}$ of $\mathrm{Hg}$. and pulse by $8 /$ minutes. Regularising the life style, avoiding excess salt, processed food, adding potassium and chlorophyll enhanced diet with timely 8 hours sleep may further reduce the overall prevalence of hypertension and prevent associated, cardiac and other complications.

\section{KEYWORDS : Hypertension, Bhramari Pranayam, Deep Abdominal Breathing, Shanmukhi Mudra, Yogic Breathing, Vit. D Deficiency}

Essential hypertension is a rise in blood pressureand in $90 \%$ it is of unknown cause.Secondary hypertension which is the result of a pathology, chronic kidney disease, narrowing of the aorta or endocrine disorder ${ }^{1}$. We ingest and excrete about $1.0 \mathrm{gm}$ of sodium that is $2.5 \mathrm{gm}$ of table salt per day. The essential hypertension develops when the kidney can not excrete this sodium which is due to sympathetic nervous system dysfunction. The predisposing factors may be singleor multiple are genetic, environmental, behavioural including work stress and food habits. Body homeostasis wants to compensateand balance it. When body defence fails hypertension is the result. There are multiple researches confirming high intake of salt results in hypertension. Obesity, diabetes, ageing, sedentary life style and low Potassium intake are the aggravating factors. $57 \%$ of deaths are due to uncontrolled hypertension leading to stroke ${ }^{2}$ and $24 \%$ deaths due to coronary heart disease because heart has to make an extra effort continuously. This also leads to thickening of blood vessels known as atherosclerosis. It is important to diagnose and manage hypertension. Stress induced hypertension responds poorly to medical management.

Physiology Of Hypertension Genetics- ten genes are there which can predispose to essential hypertension but aggravating factors are necessary to precipitate the disease ${ }^{3}$.

Autonomic nervous system- It plays a key role in maintaining cardiovascular homeostasis via pressure, volume, and chemoreceptor signals. Excess activity of the sympathetic nervous system increases blood pressure by alterations in the baroreflex and chemoreflex pathways at both peripheral and central level.

Exposure to stress increases sympathetic outflow, and repeated stress-induced vasoconstriction may result in vascular hypertrophy, atherosclerosis leading to progressive increase in peripheral resistance and blood pressure.

\section{Renin-Āngiotensin-Aldosterone System}

Maintains the extracellular fluid volume, peripheral resistance, and disturbance lead to hypertension. Being a potent constrictor of all blood vessels it acts on the musculature of arteries, raising peripheral resistance and thereby elevating blood pressure. Angiotensin II also causes the adrenal glands to release aldosterone, which stimulates the epithelial cells of the kidneys to increase re-absorption of salt and water, leading to raised blood volume and raised blood pressure. Renin angiotensin system of adipose tissue in obesity is a risk factor for hypertension and is also a factor for insulin resistance.

\section{Endothelial Dysfunction}

The endothelium of blood vessels produces an extensive range of substances that influence blood flow and, in turn, is affected by changes in the blood and the pressure of blood flow. For example, local nitric oxide and endothelin ${ }^{4}$ Potassium deficit has a critical role in hypertension. This imbalance leads to contraction of vascular smooth muscle, restricting blood flow and so driving up blood pressure. Potassium supplementation has been effective in reducing hypertension ${ }^{5}$. Deficiency of Vitamin D affects kidney function \& predisposes to poor homeostasis, deafness and hypertension ${ }^{6}$.

Patients of essential hypertension respond nicely to yoga meditation, healthy life style, consuming balance vegan diet and scheduling of the day. Subconscious stress is the key etiological factor of hypertension though not realized by majority.We must know and observe the warning signs of stress, are Headache, body ache, Tiredness, exhaustion /Trembling/shaking/Grinding teeth, clenched jaw, Cold and sweaty palms, stiffness in neck, face or shoulders, sleep problems, tachycardia Indigestion or acid reflux/Increase or loss of appetite, Weight gain/loss, Sexual difficulties.

It is the most unfortunate that majority thinks aasana as the 
main component of yoga while Patanjali Yoga Sutra emphasises in the first chapter in the first 6 lines how to control body mind and soul.

अथयोगानुशासनम्॥१।

atha yoga-anusasanam॥l॥अथयोगानुशासनम्॥So Yoga is: an introduction to the study and practice discipline | 1|| योगश्चित्तवृत्तिनिरोधः॥yogas-chitta-vratti-nirodhah ॥When you are in a state of yoga, all misconceptions (vrittis) that can exist in the mutable aspect of human beings (chitta) disappear. || 2|| तदाद्रष्टु:स्वरूपेवसस्थानम्||tadadrastuhsvarupe-'vasthanam॥For finding our true self (drashtu) entails insight into our own nature. || 3||

by follwing these you go into alpha brain wave state-a state of healing

It is a simple technique which can be easily picked up and practiced by majority in five hours training.

\section{Change Genetic Destiny}

Lets learn-- OPTIMIZE the feel good hormones level by diet/ environment, Bhramari Pranayam, focused concentration by generating Alpha, Theta and Delta Brain Waves.We have to analyse and understand the science how above practises lower the blood pressure, control the body, provide over all good health and it can lead to total transformation or kayakalp. We have to review the vagus nerve, its function vagal tone, effect of breathing and bhramari pranayama on hypertension and homeostasis.

The vagus nerves are the key conduit for efferent parasympathetic nerve activity,delivering almost all internal organs specifically to cardiovascular, respiratory, gastrointestinal, and immune systems. It affects heart rate (HR), cardiac conduction, and smooth muscle tone hence it is anti-arrhythmic anti-hypertensive and anti-inflammatory. Vagus nerve can be stimulated by Valsalva maenuvrejallandhar bandha, gag reflex-khechri mudra, Arnold nerveshanmukhi mudra, pineal gland-ajna chakra through hypothalamus and by alkaline food (gastric reflex).

Vagal Tone:- Enhanced vagal tone activates the parasympathetic nervous system. It is measured by the heart rate during breathing. Heart rate increases when we breathe in and slows down when we breathe out, bigger is the difference of inhalation- exhalation heart-rate, higher is the vagal tone. More than ten is treated as good vagal tone Higher vagal tone that is predominance of parasympathetic activity means-relaxation-alpha brain wave state of mind. It improves blood sugar regulation, reduces risk of stroke \& cardiovascular diseases, lowers B P, inhibits cytokine production hence improves digestion - better production of digestive enzymes and healing. Lower vagal tone that is predominance of sympathetic activity leads to retention of sodium in body, cardiovascular disorders, strokes, depression, diabetes, chronic fatigue syndrome, cognitive impairment, predisposes-inflammatory conditionsautoimmune diseases, rheumatoid arthritis, inflammatory bowel disease, endometriosis, autoimmune thyroid conditions, lupus hence we should learn and practice slow, deep, rhythmic, diaphragmatic or abdominal breathing.

$\begin{array}{ll}\text { Breathing Patterns And its Affects } & \\ \text { - STRESS BREATHING } & \text { YOGIC BREATHING } \\ \text { - Rapid shallow } & \text { deep abdominal } \\ \text { - Free radicals } & \text { anti oxidants } \\ \text { - 2units ATP } & 38 \text { unit ATP } \\ \text { - VATA-OSTEO CLASTIC } & \text { APOPTOSIS } \\ \text { - DEFORMITY OF TELEMERE } & \text { REPAIR } \\ \text { - Mutation-cancer } & \text { Healing }\end{array}$

Bhramari-Humming-shabad

It is a phonatory respiratory exercise releases nitric oxide. Bhramari increases the production of nitric oxide by 16 times. It is a gas molecule, key biological messenger playing an important role in biological processes at cellular level.

Nitric oxide is omnipresent a pleiotropic signalling molecule,plays important role in almost every biological system, potent vasodilator / key regulator in vascular homeostasis controls blood pressure.

Nitric Oxide enhances neural transmission / memory / apoptosis / reproduction / lipolysis / regulation of energy balance / host defence.It regulates hormone releases in hypothalamic - pituitary axis/inhibits prolactin secretion / catecholamine release / steroid genesis in adrenal gland / regulate insulin / carbohydrate metabolism. It has a role in thyrocyte / thyroid function. Nitric oxide released by Bhramari Pranayam - accelerates the microcirculation of blood and by virtue of vibration, decloggs the tiny blood vessels of brain and the body ${ }^{8}$.

\section{Brain Wave And Health}

As we age feel good hormones are released in smaller amounts including production of growth stimulating hormones hence body repair is poor and body is susceptible to deterioration/disease. Alpha theta and delta waves increase the production of all health-boosting hormones, neuropeptides, and neurotransmitters, specifically increases production of Hormones melatonin and DHEA.Production of "stress hormone" cortisol is lowered in slower brainwave bands.

Melatonin :- microbiological structure of pineal gland resembles the structure of retina and is sensitive to light (darkness) is influencedby biological clock and is dependent on light (Divya Jyoti-Ajna Chakra).

Melatonin release can be enhanced by food supplement Banana/sweet Corn/Ginger/barley/tomatoes/redwine

\section{Serotonin}

- Mood stabilizer related to the evolution .It increases the intelligence power. Amino acid tryptophan consumption increases the synthesis Gut micro biota, probiotics, pickles, apple cider vinegar, kanji and fermented food can provide up to $70 \%$ body need from intestine. Exercise, meditation, positive attitude, focused concentration increases it synthesis.

\section{MATERIAL AND METHOD}

We randomly selected 82 patients of essential hypertension from the outdoor of hospital, out of which 40 were of uncontrolled hypertension. All the subject were on antihypertensive drugs. Detailed case history, family history, duration of illness, drug type, regularity and diet pattern were questioned and recorded.All patients were looked for aggravating factors and questioned for warning signs of stress leading to hypertension.

\section{Technique:-Modified Bhramari}

Patient was instructed to take a slow deep abdominal breath, hold the breath lift the tongue and press it on the hard palate in Khechri Mudra, blow the cheek for better echo, close both ears with thumbs of both hands keeping them on concha simultaneously blocking the ear and tragus, both eyes are gently closed by index finger. The index finger should rest on lateral wall of nose. Both middle fingers are put on ala of nose, mouth is closed on both side, upper lip by ring fingers and lower lip by little fingers. Both eyes are focused in Shambhavi Mudra at the Ajnachakra in between both eye brows. Eye should be relaxed and open but eyelid closed to visualise the 
divya jyoti at Ajna Chakra. A constant rhythmic uninterrupted specific frequency sound (mouth closed) is generated. Spiritual concentration is focused on Dwarika Dhish (Diety). After complete exhalation,(hold the breath out),Vahya Kumbhak is enforced with Jallandharbandh and spiritual focus on lord Shiva(Diety).Keep holding the breath out as long as possible. Visualisation is the most important aspect of meditation,relax during the whole procedure visualise the divya jyoti at ajna chakra, give a command of relaxation achieve a thought less (shunya chittavrati) state repeat the cycle to maximise but at least 7 times.

\section{Inclusion Criteria-}

Age 35-65 years Moderate hypertension. Systolic 140180.mmof $\mathrm{Hg}$ and diastolic 90-109 $\mathrm{mm}$ of $\mathrm{Hg}$ (2017 AHA guidelines)

- On antihypertensive therapy

- No sign of cardiac complication

- Apparently healthy

- Living in the vicinity of our hospital

Exclusion Criteria-

- Cardiac or neurological Complication

- Secondary hypertension

- Thyroid disorder

- Uncontrolled diabetes mellitus

- Addiction to alcohol

- Abnormal kidney, liver function

- Irregular follow up

Blood Pressure (BP), pulse rate (PR), Oxygen saturation (Spo2) were monitored before and after meditation. The patient was instructed to sit comfortably and do Bhramari Pranayama. The data was collected, compiled tabulated and analysed for PR, BP-systolic and diastolic, oxygen saturation before and after ten minutes of meditation and Pranayam.

\section{RESULTS-}

The maximum number of patients were in the age group of 4555 years (Table I) the most common aggravating factor was sedentary life style (90\%) followed by work stress (30\%) (Table II). The commonest warning symptom was tiredness (67.5\%) followed by weight gain (62.5\%) and sleep problem (62.5\%) (Table III). The commonest warning symptom observed in our study was in male Indigestion (35\%), Pain(30\%), and tiredness while in females it was, sleep problem $(40 \%)$, acidity (40\%) and tiredness.

There was reduction of $18 \mathrm{~mm}$ systolic and $12 \mathrm{~mm} \mathrm{Hg}$ in diastolic blood pressure. Systolic BP decreased from 156+-14 to $130+-12$ and diastolic dipped from $100+-10 . \mathrm{mm}$ of $\mathrm{Hg}$ to $86+-6 \mathrm{~mm}$ of $\mathrm{Hg}$. The pulse rate dropped to average 8 beats/ minute after ten minutes of modified Bhramari Pranayam.

Table I - Age \& Sex Distribution
\begin{tabular}{|c|c|c|c|c|c|c|}
\hline \multirow{2}{*}{ Age Group } & \multicolumn{2}{|c|}{ Male } & \multicolumn{2}{c|}{ Female } & \multicolumn{2}{c|}{ Total } \\
\cline { 2 - 7 } & No. & $\%$ & No. & $\%$ & No. & $\%$ \\
\hline $35-45$ & 6 & 15 & 10 & 25 & 16 & 40 \\
\hline $45-55$ & 10 & 25 & 8 & 20 & 18 & 45 \\
\hline $55-65$ & 4 & 10 & 2 & 5 & 6 & 15 \\
\hline Total & 20 & $\mathbf{5 0 \%}$ & $\mathbf{2 0}$ & $\mathbf{5 0 \%}$ & $\mathbf{4 0}$ & $\mathbf{1 0 0 \%}$ \\
\hline
\end{tabular}

Table II - Aggravating Factors of hypertension

\begin{tabular}{|l|c|c|c|c|c|c|}
\hline \multirow{2}{*}{ Symptoms } & \multicolumn{2}{|c|}{ Male } & \multicolumn{2}{c|}{ Female } & \multicolumn{2}{c|}{ Total } \\
\cline { 2 - 8 } & No. & $\%$ & No. & $\%$ & No. & $\%$ \\
\hline Obesity & 12 & 30 & 9 & 22.5 & 21 & 52.5 \\
\hline Insomnia & 4 & 10 & 11 & 27.5 & 15 & 37.5 \\
\hline Junk Food & 2 & 5 & - & - & 2 & 5 \\
\hline Tobacco Chewing & 9 & 22.5 & 2 & 5 & 11 & 27.5 \\
\hline Alcohol Consumption & 5 & 12.5 & - & - & 5 & 12.5 \\
\hline Sedentary life style & 16 & 40 & 20 & 50 & 36 & 90 \\
\hline Work Stress & 9 & 22.5 & 3 & 7.5 & 12 & 30 \\
\hline Diabetes & 5 & 12.5 & 8 & 20 & 13 & 32.5 \\
\hline
\end{tabular}

Table III - Warning Signs of Stress

\begin{tabular}{|c|c|c|c|c|c|c|c|}
\hline \multirow{2}{*}{ Symptoms } & \multicolumn{2}{|c|}{ Male } & \multicolumn{2}{c|}{ Female } & \multicolumn{2}{c|}{ Total } \\
\cline { 2 - 8 } & No. & $\%$ & No. & $\%$ & No. & $\%$ \\
\hline Headache & 3 & 7.5 & 8 & 20 & 11 & 27.5 \\
\hline Body ache & 8 & 20 & 11 & 27.5 & 19 & 47.5 \\
\hline Tiredness & 11 & 27.5 & 16 & 40 & 27 & 67.5 \\
\hline $\begin{array}{c}\text { Exhaustion/Trembling/Shaking } \\
\text { Teeth }\end{array}$ & 2 & 5 & 9 & 22.5 & 11 & 27.5 \\
\hline Clenched Jaw/Grinding & - & & 1 & 2.5 & 1 & 2.5 \\
\hline Cold and Sweaty Palms & 5 & 12.5 & 9 & 22.5 & 14 & 35 \\
\hline Stiffness in neck Face or & 12 & 30 & 7 & 17.5 & 19 & 47.5 \\
\hline Shoulders & & & & & & \\
\hline Sleep Problems & 9 & 22.5 & 16 & 40 & 25 & 62.5 \\
\hline Tachycardia & 2 & 5 & 8 & 20 & 10 & 25 \\
\hline $\begin{array}{c}\text { Indigestion or acid } \\
\text { reflux/increase/loss of appetite }\end{array}$ & 14 & 35 & 16 & 40 & 30 & 75 \\
\hline Weight Gain & 12 & 30 & 13 & 32.5 & 25 & 62.5 \\
\hline Sexual Difficulties & 9 & 22.5 & 6 & 15 & 15 & 37.5 \\
\hline
\end{tabular}

Table IV - Response of Bhramari Pranayama on vitals

\begin{tabular}{|l|c|c|}
\hline & Before Bhramari & After Bhramari \\
\hline Systolic & $156 \pm 14$ & $130 \pm 12$ \\
\hline Diastolic & $100 \pm 10$ & $86 \pm 6$ \\
\hline Pulse Rate & $82 \pm 8$ & $74 \pm 6$ \\
\hline
\end{tabular}

\section{DISCUSSION}

In our study there was significant reduction of mean systolic $18 \mathrm{~mm}$ and diastolic $12 \mathrm{~mm} \mathrm{Hg}$ of blood pressure.

The higher pulse rate may be due to higher sympathetic activity, while Parasympathetic predominance, corticohypothalamomedullary inhibition and release of DHEA helps in reduction of heart rate. It is a sign of improved cardiac efficiency.

In previous study Arora and dubey has observed by chanting Om for five Minutes a fall of $14 / 05 \mathrm{~mm}$ of $\mathrm{Hg}^{9}$.Previous studies conducted by Barnesetal has observed similar results ${ }^{10}$.

In a Cochrane review conducted by Hartley et al. diastolic blood pressure was lowered significantly in majority of studies ${ }^{11}$.

The Bhramri Pranayam deep abdominal breathing reduces sympathetic activity, enhances parasympathetic activity, enhances homeostasis leading to release of DHEA and serotonin.

If we keep in mind and observe the warning symptoms and avoid aggravating factors by scheduling the day, healthy potassium rich diet with exercise (Yoga) hypertension is hundred percent preventable.

\section{CONCLUSION-}

Bhramri Pranayam, focused concentration (Shiv Dhyan) and slow deep abdominal breathing with extended exhalation leads to calmness reduces hyperactive sympathetic activity and enhances parasympathetic activity. The average lowering of blood pressure was observed by $18 / 12 \mathrm{~mm}$ of $\mathrm{Hg}$. and pulse by $8 /$ minutes. Regularising the life style, avoiding excess salt, processed food, adding potassium and chlorophyll enhanced diet with timely 8 hours sleep may further reduce the overall prevalence of hypertension and prevent associated, cardiac and other complications. Limiting the ambitions (Aparigrah) and converting distress to eustress by positive attitude yognidra and meditation may result in life time benefit.

\section{REFERENCES:-}

1. Carretero OA, Oparil S (January 2000). "Essential hypertension. Part I: definition and etiology". Circulation. 101 (3): 329-] 35. doi:10.1161/01. CIR.101.3.329. PMID 10645931. Retrieved 2009-06-05.

2. Deepa T, Gowri S, Thirrunavukkarasu N. Effect of yoga and meditation on 
mild to moderate essential hypertensives. J ClinDiagRes ; 6:21-6.

3. Oparil S, Zaman MA, Calhoun DA (November 2003). "Pathogenesis of hypertension". Ann. Intern. Med. 139 (9): 761-76. doi:10.7326/0003-4819-139-9200311040-00011. PMID 14597461.

4. Touyz RM, Schiffrin EL (June 2003). "Role of endothelin in human hypertension". Canadian Journal of Physiology and Pharmacology. 81 (6): 533-41. doi:10.1139/y03-009. PMID 12839265.

5. Adrogué, HJ: Madias, NE (10 May 2007). "Sodium and potassium in the pathogenesis of hypertension" (PDF). The New England Journal of Medicine. 356 (19): 1966-78. doi:10.1056/NEJMra064486. PMID 17494929.

6. Taneja MK, Taneja V. Vitamin D deficiency in E.N.T. Patients. Indian J Otolaryngol Head Neck Surg 2013;65:57-60.

7. Taneja MK. Frequency-modulated Bhramari Pranayam in tinnitus and deafness. Indian J Otol [serial online] 2018 [cited 2019 Nov 10]; 24:209-13. Available from: http://www.indianjotol.org/text.asp? 2018/24/4/209/254223

8. Taneja MK. Nitric Oxide Bhramari Prnayam and deafness. Indian J Otol 2016;22:1-3

9. Jyoti Arora, Namrata Dubey Immediate benefits of "Om" chanting on blood pressure and pulse rate in uncomplicated moderate hypertensive subjects. Natl J Physiol Pharma Pharmacol. 2018; 8(8): 1162-1165. Doi:10.5455/njppp. 2018.8.0413425042018

10. Barnes, Vernon A, Frank A, Treiber, Davis H. Impact of transcendental Meditation on cardiovascular function at rest and during acute stress in adolescents with high normal blood pressure. Journal of Psychosomatic Research 2001,51 (4):597-60.

11. Hartley L, Dyakova M, Holmes J, Clarke A, Lee MS, Ernst E, Rees K: Yoga for the primary prevention of cardiovascular disease. Cochrane Libr. 2014; (5). [PubMed] 